\title{
Quantitative Analyses of Nine Phenolic Compounds and Their Antioxidant Activities from Thirty-Seven Varieties of Raspberry Grown in the Qinghai-Tibetan Plateau Region
}

\author{
Yuwei Wang ${ }^{1,+}{ }^{,}$Jian Liang ${ }^{1,+}$, Guangxiang Luan ${ }^{2} \oplus$, Shoude Zhang ${ }^{1}$, Yixi Zhuoma ${ }^{1}$, \\ Jiuxiang Xie ${ }^{1}$ and Wu Zhou ${ }^{1, *(1)}$ \\ 1 State Key Laboratory of Plateau Ecology and Agriculture, Qinghai University, Xining 810016, China; \\ wangyuwei0507@163.com (Y.W.); liangjianws@126.com (J.L.); shoude.zhang@foxmail.com (S.Z.); \\ yixizhuoma8899@126.com (Y.Z.); xiejiuxiang8817@163.com (J.X.) \\ 2 Key Laboratory of Tibetan Medicine Research, Northwest Institute of Plateau Biology, Chinese Academy of \\ Sciences, Xining 810016, China; gxluan@nwipb.cas.cn \\ * Correspondence: zhouwu870624@163.com \\ + These authors contributed equally to this article.
}

Received: 12 September 2019; Accepted: 29 October 2019; Published: 31 October 2019

\begin{abstract}
In this work, an efficient method for the rapid extraction and separation of antioxidant phenols was developed and optimized. The method was then applied to extract and separate nine phenols from 37 varieties of raspberry, in which their antioxidant activities were further investigated. First, the extraction was conducted using ultra-sonication, which was then further separated using reversed-phase high-performance liquid chromatography/ultraviolet (RP-HPLC/UV) analysis. In this step, several key parameters (volume of the extraction reagent, time of extraction, and the temperature of extraction) affecting its efficiency were investigated and optimized using the response surface methodology (RSM) combined with the Box-Behnken design (BBD) so that the optimal conditions were obtained. According to the overall results of the optimization study, the optimal conditions were chosen as follows: volume of extraction reagent $=2.0 \mathrm{~mL}$, time of extraction $=50.0 \mathrm{~min}$, and temperature of extraction $=50^{\circ} \mathrm{C}$. The optimal conditions were then applied to extract nine phenols, including gallic acid, catechin, chlorogenic acid, vanillic acid, syringic acid, cumaric acid, ferulic acid, rosemary acid, and quercetin from 37 raspberry varieties. The extracted phenols were characterized and their antioxidant activities, including $\mathrm{DPPH}^{-}$and $\mathrm{ABTS}^{-}$free radical scavenging and intracellular reactive oxygen species (ROS) activity, using HepG2 cells as the model, were subsequently studied. The findings suggested that although their contents varied among most raspberry varieties, these phenols significantly contributed toward their antioxidant capacity and scavenging intracellular ROS activities. This study provides a scientific and theoretical basis for the selection of raspberry varieties and product development in Qinghai province.
\end{abstract}

Keywords: RP-HPLC/UV; raspberry; phenols; RSM; antioxidant activity

\section{Introduction}

Raspberry (Rubus corchorifolius L. $f$ ) belongs to the family Rosaceae, the subfamily Rosoideae, and the genera Rubus. The plant has high levels of flavonoids [1,2], anthocyanins [3,4], phenols [5], vitamin C, dietary fibers, tocotrienol, calcium, magnesium, linoleic acid, and carotenoids [6].

Phenols, the phenylpropanoid compounds derived from phenylalanine and the tyrosine metabolic pathways, are active, natural antioxidant compounds found in various plants [7]. Various studies 
have shown that phenols play important roles as antioxidants against free radicals and other reactive oxygen species (ROS), which are the major cause of many chronic human diseases, such as cancer and cardiovascular diseases [8-10]. Moreover, phenols from the cranberry plant and its products have been shown to have rich biological activities involving anticarcinogenic [11], antimutagenic [12], antibacterial [13], antioxidant, and antiradical properties [14], which are evident from various in vitro and animal model studies. In addition, some of the phenol derivatives, such as ferulic acid, caffeic, and p-coumaric acid, have been described to be important functional compounds that contain decent antioxidant activities [8]. Furthermore, as one of the most abundant phenol derivatives, rosmarinic acid has been extensively utilized in the pharmaceutical and cosmetic industries because it has a high antioxidant activity [15]. Despite the above, bioactive compounds derived from berries are still rarely identified and extracted because of their low content, and the complex composition of berries leads to a high content of other compounds that interfere with extraction and separation.

Because of their structures (Figure 1), phenols have a limited absorbance selectivity in the ultraviolet region. Because of this property, the most commonly used method for the determination of phenolic compounds is based on high-performance liquid chromatography (HPLC) separation [16,17]. High-performance liquid chromatography-electrospray ionization-mass spectrometry (HPLC-ESI-MS) [18], high-performance liquid chromatography-diode array detection-electrospray ionization-mass spectrometry (HPLC-DAD-ESI-MS) [19], and high-resolution MS [20] can be used to determine the total phenol content, which provides information on the molecular mass and structural features of components, and they are considered to be more useful than other methods of separation, identification, and quantification of the characteristic compounds. However, since these methods are quite costly when achieving short analysis times, or long analysis times with common equipment, many studies [21-23] have used high-performance liquid chromatography/ultraviolet (HPLC/UV) detection, which is less costly, decreases the runtime, is comparably convenient to operate, minimizes wear on various HPLC system components, and is suitable for routine analysis for the determination of phenolic compounds. Studies describing the methodology for determining phenolic compounds in raspberry plants grown in the Qinghai-Tibetan Plateau region using reversed-phase high-performance liquid chromatography/ultraviolet (RP-HPLC/UV) have not been found. Extraction is the initial process, and it is also an essential step in the recovery and purification of phenolic compounds from raspberries. The efficiency of extraction depends on several key parameters, such as the volume of the extraction reagent, time of extraction, the temperature of extraction, and $\mathrm{pH}$, and their effects can be either independent or interactive. In this study, the response surface methodology (RSM) combined with the Box-Behnken design (BBD) was used to statistically evaluate the effects of multiple factors and their interactions. Therefore, it is of great importance that sensitive and accurate extraction and separation methods of phenolic compounds from berries are established.

Raspberry planting is a labor-intensive industry with high labor costs. In recent years, raspberry production has been stagnant or has shrunk in developed countries, such as those in Europe and the United States, and many western European countries are withdrawing from the raspberry production field. Therefore, the demand gap for raspberries is constantly expanding. At present, raspberry planting is growing rapidly in some developing countries. Thirty-seven varieties of raspberry are grown in the Qinghai-Tibetan plateau region, including 9 local varieties and 28 adventitious varieties. In this work, an efficient method for the rapid extraction and separation of phenols was developed, and several key parameters affecting its efficiency were optimized using a Box-Behnken design (BBD) in accordance with the response surface methodology (RSM). The optimized methods were then applied to an analysis of 9 phenols including gallic acid, catechin, chlorogenic acid, vanillic acid, syringic acid, cumaric acid, ferulic acid, rosemary acid, and quercetin from 37 varieties of raspberry grown in the Qinghai-Tibetan Plateau region. The raspberry-extracted phenols were further tested for their antioxidant activities, including scavenging activities against 1,1-diphynyl-2-picrylhydrazyl (DPPH) and 2,2' -azino-bis(3-ethylbenzothiazoline-6-sulfuric acid) (ABTS) free radicals, as well as intracellular 
reactive oxygen species (ROS) using HepG2 cells as the model. To the best of our knowledge, this is the first reported extraction, separation, and analysis of phenols and their antioxidative activities from 37 varieties of raspberry grown in the Qinghai-Tibetan Plateau region, and this study provides a scientific basis for the selection of raspberry varieties and product development.

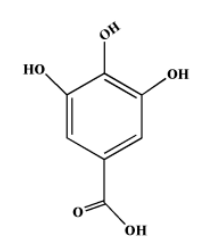

Gallic acid<smiles>CC(C)(C)C(C)(Cl)c1ccccc1</smiles>

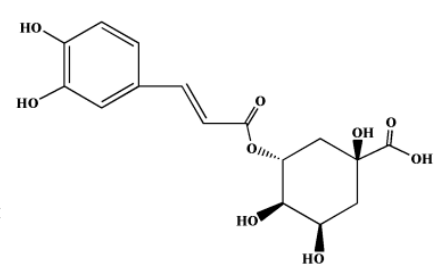

Chlorogenic acid<smiles>COc1cc(C(=O)O)ccc1O</smiles>

Vanillic Acid<smiles>COc1cc(C(=O)O)cc(OC)c1C</smiles>

Syringic acid

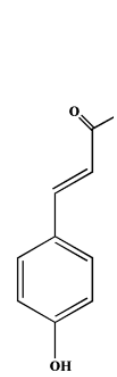

Coumaric acid

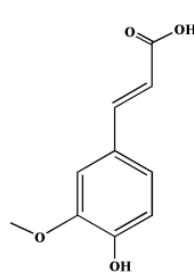

Ferulic acid

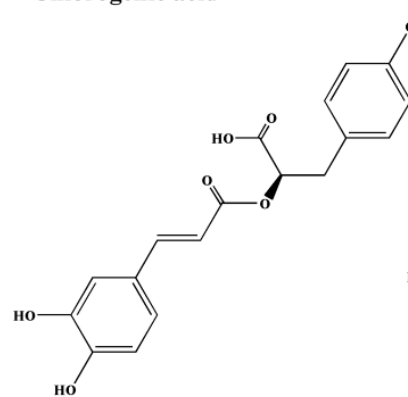

Rosmarinic acid

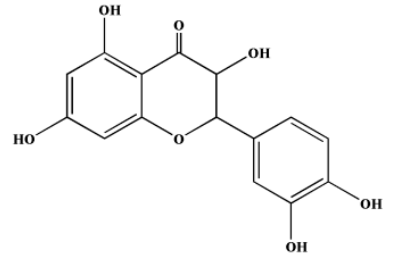

Quercetin

Figure 1. The chemical structures of nine phenols.

\section{Results and Discussion}

\subsection{Optimization of the Extraction Conditions}

In order to obtain the best extraction conditions, a BBD was employed to optimize the significant variables, as well as to further investigate interactions between these variables. The examined levels and experimental results are listed in Table 1. The large "model F-value" of 24.37 indicated that the model was significant, with the chance of only $0.02 \%$ that this might be due to noise. Moreover, the

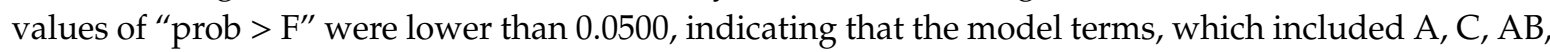
$A^{2}, B^{2}$, and $C^{2}$, were significant. This means that the volume of extraction reagent, the temperature of extraction, interaction of the volume of extraction reagent, and the time of extraction were, indeed, key parameters affecting the extraction efficiency. The "lack of fit F-value" of 7.79 implied that it was significant, with a $3.80 \%$ probability that this occurred due to noise. The empirical second-order polynomial model for the extraction design is shown in the following equation:

$$
\begin{aligned}
Y_{1}=+5154.02+ & 28.02 \times A+11.02 \times B+26.71 \times C+20.91 \times A B+17.07 \times A C \\
& -4.29 \times B C-67.26 A^{2}-46.32 B^{2}-49.33 C^{2}
\end{aligned}
$$

Based on the optimal conditions, three-dimensional response surfaces (Figure 2a-c) were plotted to investigate the interactions among the variables in order to determine the optimization of each factor for the maximum content of phenols. Figure 2a shows the combined effect of the volume of extraction reagent and the time of extraction. Figure $2 b$ highlights the volume of extraction reagent and the temperature of extraction. Figure 2c depicts the combined effects of the time of extraction and the temperature of extraction. According to the overall results of the optimization study, the optimal conditions were chosen as follows: volume of extraction reagent $=2.0 \mathrm{~mL}$, time of extraction $=50.0$ $\mathrm{min}$, and the temperature of extraction $=50^{\circ} \mathrm{C}$. 
Table 1. Experimental design and data for the best extraction conditions obtained from BBD for phenolic acids $(n=3)$.

\begin{tabular}{ccccc}
\hline Run & $\begin{array}{c}\text { Volume of Extraction } \\
\text { Reagent }(\mathbf{m L})\end{array}$ & $\begin{array}{c}\text { Time of Extraction } \\
(\mathbf{m i n})\end{array}$ & $\begin{array}{c}\text { Temperature of } \\
\text { Extraction }\left({ }^{\circ} \mathbf{C}\right)\end{array}$ & Peak Area \\
\hline 1 & 1.50 & 40.00 & 55.00 & 5097.98 \\
2 & 1.50 & 50.00 & 45.00 & 5153.31 \\
3 & 1.00 & 60.00 & 45.00 & 5011.27 \\
4 & 2.00 & 50.00 & 35.00 & 5028.35 \\
5 & 1.50 & 60.00 & 55.00 & 5089.75 \\
6 & 1.50 & 50.00 & 45.00 & 5167.35 \\
7 & 1.00 & 40.00 & 45.00 & 5009.34 \\
8 & 1.50 & 50.00 & 45.00 & 5145.27 \\
9 & 2.00 & 40.00 & 45.00 & 5027.78 \\
10 & 1.50 & 60.00 & 35.00 & 5027.31 \\
11 & 2.00 & 50.00 & 55.00 & 5098.31 \\
12 & 1.00 & 50.00 & 35.00 & 5010.68 \\
13 & 1.50 & 50.00 & 45.00 & 5149.74 \\
14 & 1.00 & 50.00 & 55.00 & 5012.35 \\
15 & 1.50 & 40.00 & 35.00 & 5018.39 \\
16 & 1.50 & 50.00 & 45.00 & 5154.41 \\
17 & 2.00 & 60.00 & 45.00 & 5113.34 \\
\hline
\end{tabular}

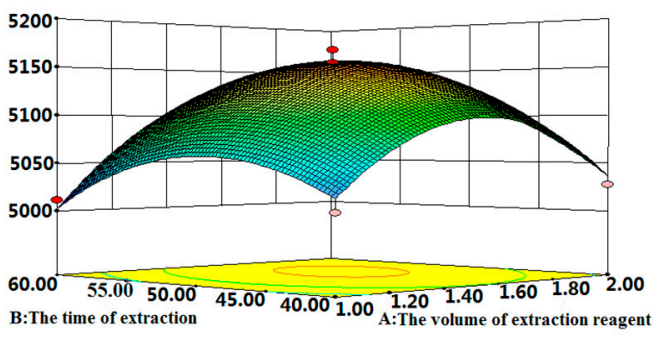

(a)

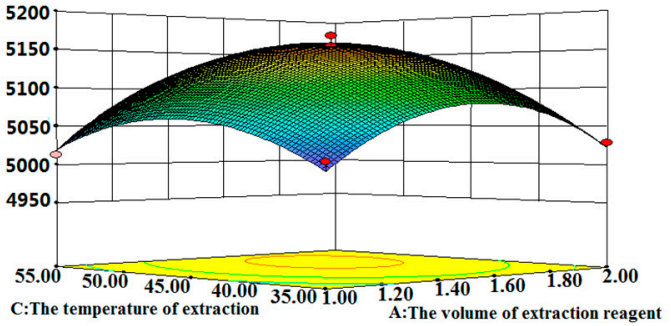

(b)

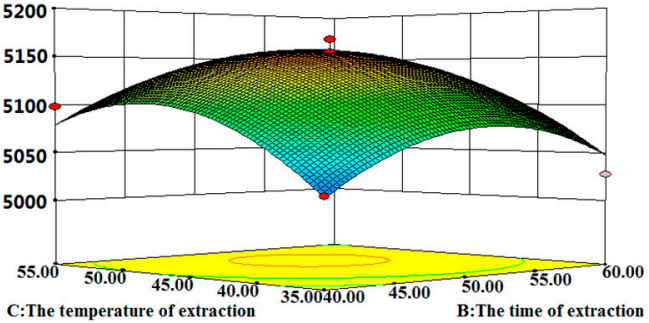

(c)

Figure 2. 3D surface plot showing the significant interaction effects of the extraction parameters: (a) the volume of extraction reagent and the time of extraction, (b) the volume of extraction reagent and the temperature of extraction, and (c) the time of extraction and the temperature of extraction.

\subsection{Optimization of HPLC Separation}

To obtain the optimal HPLC separation conditions, several chromatographic parameters were investigated-chromatographic columns including Hypersil ${ }^{\mathrm{TM}}$ BDS C8 $(200 \mathrm{~mm} \times 4.6 \mathrm{~mm}, 5 \mu \mathrm{m}$, Thermo Fisher Scientific, Waltham, MA, USA), Agilent Zorbax C18 (250 mm $\times 4.6 \mathrm{~mm}, 5 \mu \mathrm{m}$, Agilent Technologies Co. Ltd., Palo Alto, CA, USA), Spherisorb ${ }^{\circledR}$ C18 $(200 \mathrm{~mm} \times 4.6 \mathrm{~mm}, 5 \mu \mathrm{m}$, Waters, Milford, MA, USA), Zorbax Eclipse XDB-C8 $(150 \mathrm{~mm} \times 4.6 \mathrm{~mm}, 5 \mu \mathrm{m}$, Agilent Technologies Co. Ltd., Palo Alto, CA, USA), Hypersil ${ }^{\mathrm{TM}}$ GOLD $(250 \mathrm{~mm} \times 4.6 \mathrm{~mm}, 5 \mu \mathrm{m}$, Thermo Fisher Scientific, Waltham, MA, USA), and Hypersil C18 (200 mm $\times 4.6 \mathrm{~mm}, 5 \mu \mathrm{m}$, Thermo Fisher Scientific, Waltham, MA, USA), along with their separation efficiencies, were compared. The results indicated that the Hypersil ${ }^{\mathrm{TM}}$ GOLD $(250 \mathrm{~mm} \times 4.6 \mathrm{~mm}, 5 \mu \mathrm{m})$ column had the highest separation efficiency among all columns 
investigated. In the mobile phase, in which acetonitrile-water and methanol-water were compared, the results showed that a more symmetric separation peak was obtained when acetonitrile-water was used as the mobile phase. Based on the above results, the chromatographic conditions, which are considered optimal, were as follows: analytical column, Hypersil ${ }^{\mathrm{TM}}$ GOLD $(250 \mathrm{~mm} \times 4.6 \mathrm{~mm}, 5 \mu \mathrm{m})$ column; temperature, $30{ }^{\circ} \mathrm{C}$; and mobile phase, acetonitrile-water. Other conditions were (1) elution conditions, including two types of eluents: eluent A ( $0.3 \%$ methanoic acid aqueous solution) and eluent B (5\% acetonitrile and 0.3\% methanoic acid aqueous solution); (2) flow steps of eluent B: 98\%-95\% from 0-8 $\mathrm{min}, 95 \%-89.5 \%$ from $8-18 \mathrm{~min}, 89.5 \%-89.5 \%$ from $18-21 \mathrm{~min}, 89.5 \%-75 \%$ from $21-30 \mathrm{~min}$, and 75\%-0\% from 30-35 min; and (3) sample injection volume: $10 \mu \mathrm{L}$. In addition, prior to each analysis, the column was pre-equilibrated with the mobile phase for $5 \mathrm{~min}$. The HPLC chromatograms of the blank sample, standard solutions, and the extracted samples are presented in Figure 3.
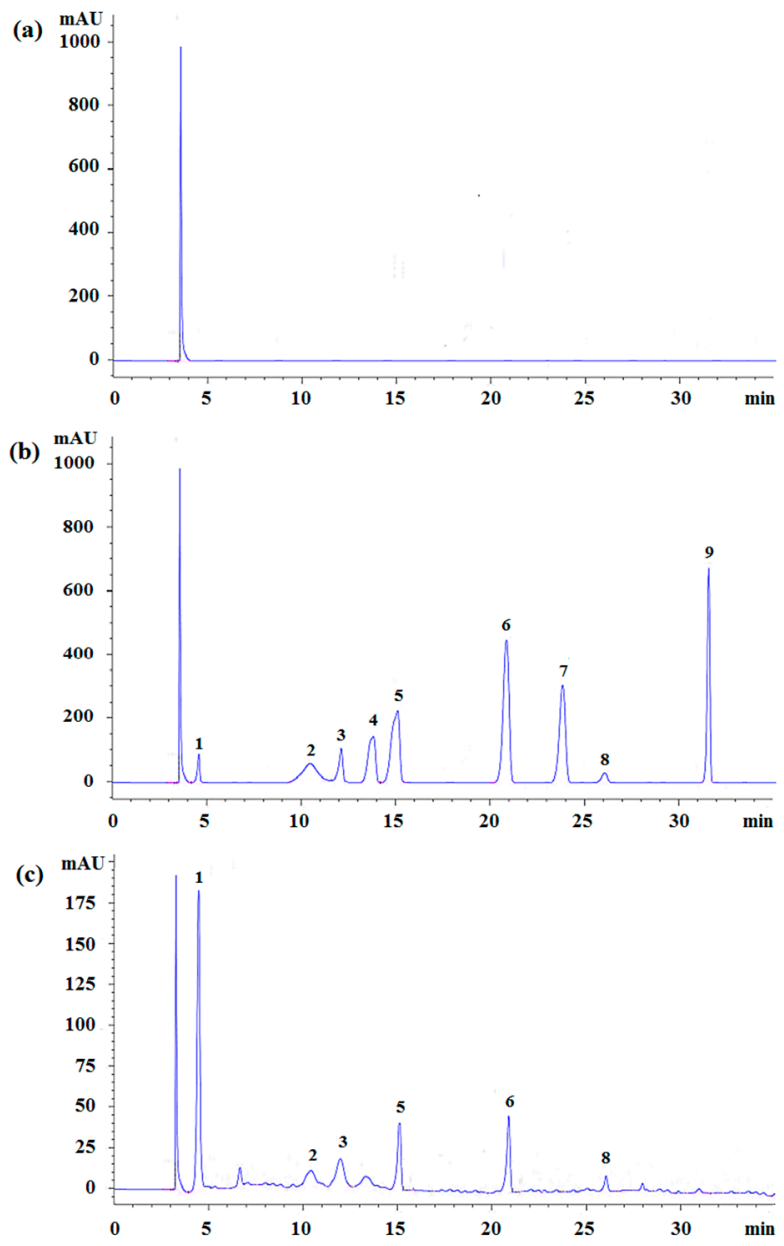

Figure 3. The representative chromatograms for blank (a), standards (b), and the typical chromatograms for the nine phenols in Canby (c). Peak labels: 1-gallic acid, 2-catechin, 3-chlorogenic acid, 4-vanillic acid, 5-syringic acid, 6-cumaric acid, 7-ferulic acid, 8-rosemary acid, and 9-quercetin.

\subsection{Validation of the Method}

The optimized method was validated for its linearity, limits of detection (LODs), the limits of quantification (LOQs), precision, and accuracy. Linearity data were obtained by a plot of the peak areas versus concentrations for nine phenol standards. As summarized in Table 2, all phenols showed excellent linear responses with coefficients of $>0.9962$. In addition, the LOD and LOQ ranges were from 0.12 to $0.49 \mathrm{ng} / \mathrm{mL}$ and 0.35 to $1.02 \mathrm{ng} / \mathrm{mL}$, respectively. The instrument precision determined based on phenols was lower than 1.1 and 1.4, respectively, for the inter-day and intra-day validations 
(Table 2). The percent recoveries were determined by comparing the concentrations obtained from spiked samples (conducted by spiking three different concentrations of samples into standards) with that of the actual sample amount added. As reported in Table 3, the percent recoveries ranged from $94.0 \%$ to $101.1 \%$. These results demonstrated that this method was a precise and practical method, suitable for the determination of phenols extracted from the raspberries.

Table 2. Linear regression equation, correlation coefficients, limits of detection (LODs), limits of quantification (LOQs), reproducibility of retention time and peak area, and intra- and inter-day precisions.

\begin{tabular}{|c|c|c|c|c|c|c|c|c|}
\hline \multirow[t]{2}{*}{ Analyte } & \multirow{2}{*}{$\begin{array}{l}\text { Regression } \\
\text { Equation }\end{array}$} & \multirow[t]{2}{*}{$\mathbf{r}$} & \multirow[t]{2}{*}{$\begin{array}{l}\text { LOD } \\
(\mu \mathrm{g} / \mathrm{L})\end{array}$} & \multirow[t]{2}{*}{$\begin{array}{l}\mathrm{LOQ} \\
(\mu \mathrm{g} / \mathrm{L})\end{array}$} & \multicolumn{2}{|c|}{$\begin{array}{l}\text { Instrument Precision } \\
\qquad(n=6)\end{array}$} & \multicolumn{2}{|c|}{$\begin{array}{l}\text { Method Precision } \\
\qquad(n=3)\end{array}$} \\
\hline & & & & & Intra-Day & Inter-Day & Intra-Day & Inter-Day \\
\hline Catechin & $y=3.925 x-0.280$ & 0.9962 & 0.30 & 0.97 & 0.6 & 1.0 & 1.3 & 2.5 \\
\hline Chlorogenic acid & $y=1.790 x-0.029$ & 0.9973 & 0.32 & 0.99 & 0.8 & 1.3 & 1.7 & 3.5 \\
\hline Cumaric acid & $y=10.132 x-0.139$ & 0.9968 & 0.18 & 0.57 & 1.1 & 1.4 & 1.7 & 3.4 \\
\hline Ferulic acid & $y=7.101 x-0.073$ & 0.9963 & 0.23 & 0.69 & 0.7 & 1.1 & 1.4 & 2.9 \\
\hline Rosemary acid & $y=0.657 x-0.002$ & 0.9972 & 0.32 & 0.98 & 0.5 & 0.8 & 1.2 & 2.3 \\
\hline Quercetin acid & $y=7.023 x-0.061$ & 0.9977 & 0.11 & 0.35 & 0.7 & 1.0 & 1.5 & 3.3 \\
\hline
\end{tabular}

Table 3. Recovery studies of the proposed method at three concentration levels.

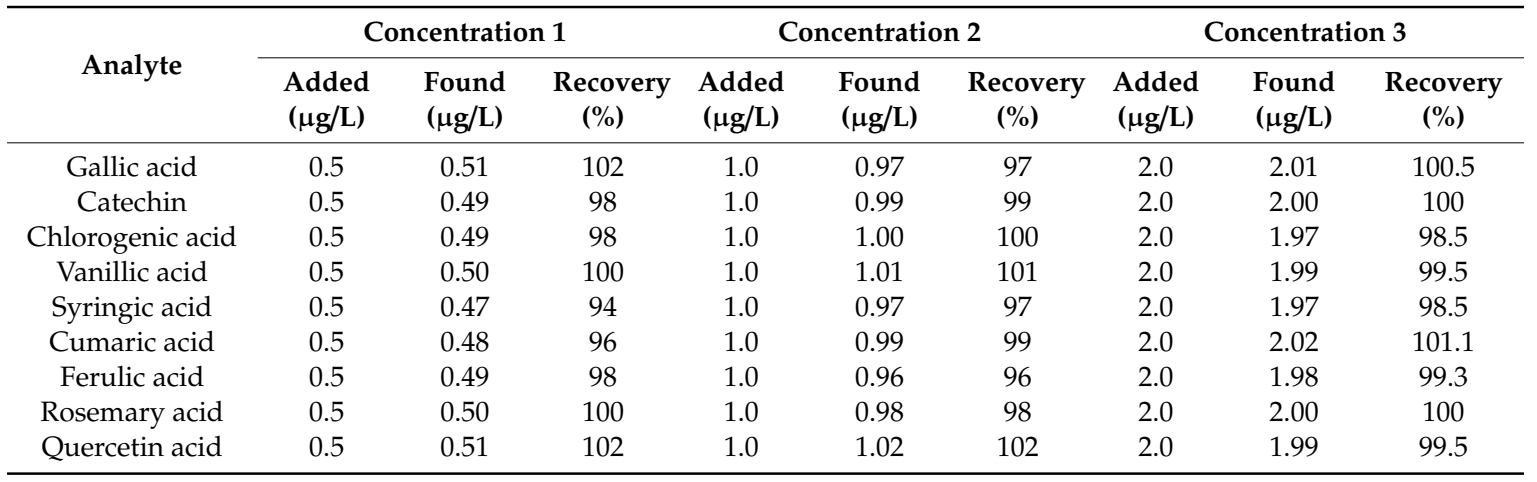

\subsection{Analysis of 9 Phenols from 37 Raspberry Varieties}

The established method, as well as its optimal conditions, was further applied to analyze 9 phenols from 37 raspberry varieties: 28 adventitious varieties (Meeker, Boyne, Tulameen, Fortodi, Lauren, Canby, Taylor, Tulameen, Reveille, Coho, Encore, Herokee, Kitsilano, Chilcotin, Titan, Latham, Raspberry Nano, Chillieack, Triple Crown, Boysenberry, Shawnee, Honey Queen, Full of Red Raspberry, Autumn Britten, Autumn Bliss, Heritage, Killarney, and Kiwigold), and 9 local varieties (Laguo, Cangjia, Baojia, Leren, Nanque, Ganchong, Pansheng, Layun, and Huazang). The composition data of the nine phenols in the dry materials are expressed as mean \pm SD $(n=3)$ and summarized in Table 4 . The data showed that the contents of 9 phenols from 37 raspberry varieties were significantly different, in which the content from the adventitious varieties was higher than that from the local varieties. Moreover, the contents of gallic acid, catechin, chlorogenic acid, syringic acid, and cumaric acid were highest in the adventitious varieties of Tulameen $(195.51 \mathrm{mg} / \mathrm{g})$, Coho $(59.69 \mathrm{mg} / \mathrm{g})$, Shawnee $(391.60 \mathrm{mg} / \mathrm{g})$, Full of Red Raspberry (313.78 mg/g), and Meeker (198.21 mg/g). In addition, the contents of vanillic acid, ferulic acid, and quercetin acid were found to be very low. The content of rosemary acid was less 25.06 $\mathrm{mg} / \mathrm{g}$, except for Encore $(38.55 \mathrm{mg} / \mathrm{g}$ ) and Boysenberry $(33.62 \mathrm{mg} / \mathrm{g}$ ) varieties.

The phenolic compound contents of the raspberries growing in different regions were significantly different [24,25]. The content of ferulic acid in raspberry cultivars grown in Turkey was $6.39 \mathrm{mg} / \mathrm{g}$, which was higher than that of raspberry cultivars grown in the Qinghai-Tibetan Plateau region [24]. 
The content of quercetin in raspberry cultivars grown in Turkey was $0.35 \mathrm{mg} / \mathrm{g}$, and it was found that only Boyne contained quercetin among raspberry cultivars grown in the Qinghai-Tibetan Plateau region. The phenolic compositions of raspberries were quite different between those grown in Poland and the Qinghai-Tibetan Plateau region [25]. In addition, the amount of total phenolic compound in extracts was determined according to the Folin-Ciocalteu's procedure in order to prepare with other studies concerning rasberries from other geographic places. As shown in Table 5, the total phenolic compound contents of Heritage and Meeker growing in Qinghai-Tibetan Plateau was much higher than Northern Greece, New York and so on. The total phenolic compound contents of Autumn Bliss in Qinghai-Tibetan Plateau was lower than Northern Greece but higher than Spain, Belgrade, Brazil, New York. The total phenolic compound contents of Taylor, Boysenberry, Kiwigold, Autumn Britten, Boyne, Tulameen, Coho planted in different areas were also significantly different. These variations in phenol content might be due to differences in physical and climatic environments, such as temperature, soil, moisture, wind, humidity, sunlight, and so on.

\subsection{Analysis of Antioxidant Activities}

\subsubsection{The DPPH and ABTS Free Radical Scavenging Activities}

According to Figure 4a,b, the phenols extracted from the raspberry possessed high antioxidant activities and could effectively and rapidly inhibit the formation of DPPH and ABTS free radicals in solution. Furthermore, Boyne, at a concentration of $100 \mu \mathrm{g} / \mathrm{mL}$, showed scavenging ratios up to $61.77 \%$ and $48.98 \%$ against DPPH and ABTS free radicals, respectively. The top five scavenging abilities of raspberry-extracted phenols against ABTS, from the highest to the lowest, were: Baojia, Meeker, Tulameen, Boyne, and Laguo. Additionally, the inhibition ratio against the DPPH free radical was significantly higher than that against the ABTS free radical, indicating that the scavenging ability of phenols was more favorable against lipo-soluble free radicals (DPPH) than that against hydro-soluble free radicals (ABTS).

(a)

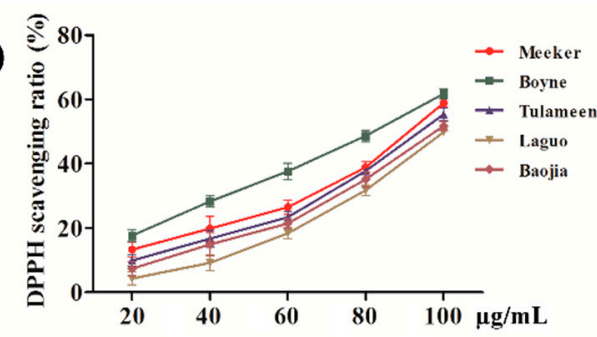

(c)

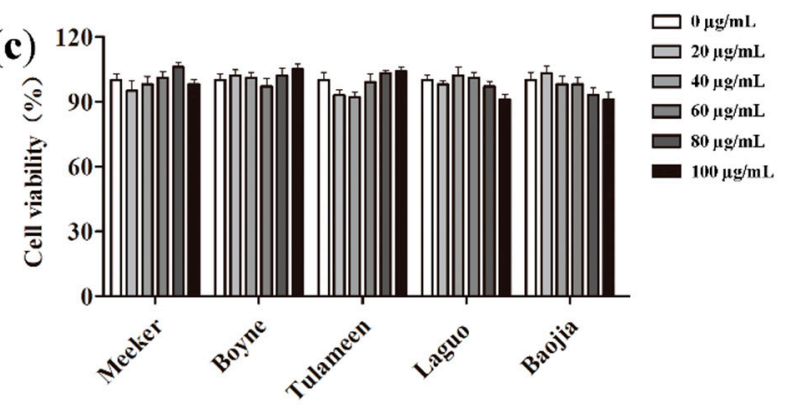

(b)

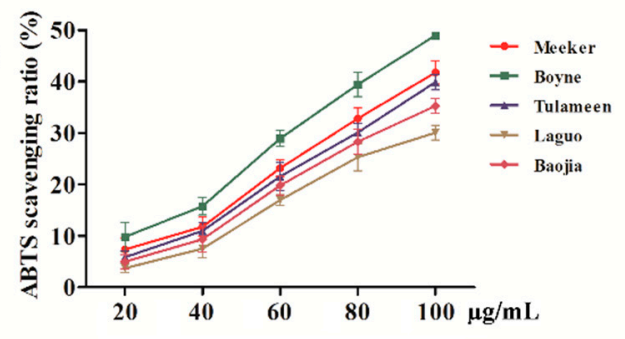

(d)

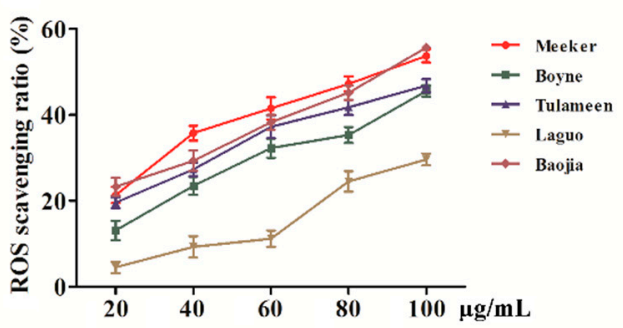

Figure 4. Analysis of antioxidant activities: (a) 1,1-diphenyl-2-picrylhydrazyl (DPPH) scavenging ratio, (b) 2, 2'-azino-bis(3-ethylbenzothiazoline-6-sulfonic acid) (ABTS) scavenging ratio, (c) cell viability, and (d) reactive oxygen species (ROS) scavenging ratio. 
Table 4. Main phenolic acid contents in Rubus idaeus L. (mean \pm SD).

\begin{tabular}{|c|c|c|c|c|c|c|c|c|c|}
\hline Samples & $\begin{array}{c}\text { Gallic Acid } \\
(\mathrm{mg} / \mathrm{g}, n=3)\end{array}$ & $\begin{array}{c}\text { Catechin } \\
(\mathrm{mg} / \mathrm{g}, n=3)\end{array}$ & $\begin{array}{c}\text { Chlorogenic Acid } \\
\quad(\mathrm{mg} / \mathrm{g}, n=3)\end{array}$ & $\begin{array}{l}\text { Vanillic Acid } \\
(\mathrm{mg} / \mathrm{g}, n=3)\end{array}$ & $\begin{array}{c}\text { Syringic Acid } \\
(\mathrm{mg} / \mathrm{g}, n=3)\end{array}$ & $\begin{array}{l}\text { Cumaric Acid } \\
(\mathrm{mg} / \mathrm{g}, n=3)\end{array}$ & $\begin{array}{l}\text { Ferulic Acid } \\
(\mathrm{mg} / \mathrm{g}, n=3)\end{array}$ & $\begin{array}{l}\text { Rosemary Acid } \\
(\mathrm{mg} / \mathrm{g}, n=3)\end{array}$ & $\begin{array}{l}\text { Quercetin Acid } \\
\quad(\mathrm{mg} / \mathrm{g}, n=3)\end{array}$ \\
\hline Meeker & $145.87 \pm 0.63$ & $30.57 \pm 0.89$ & $77.00 \pm 0.68$ & - & $189.30 \pm 0.28$ & $198.21 \pm 0.67$ & - & $10.92 \pm 0.22$ & - \\
\hline Boyne & $36.74 \pm 0.42$ & $9.91 \pm 0.40$ & $20.37 \pm 0.46$ & $5.03 \pm 0.74$ & - & $26.89 \pm 0.75$ & - & $21.43 \pm 0.46$ & $5.60 \pm 0.44$ \\
\hline Tulameen & $77.74 \pm 0.97$ & $2.39 \pm 0.81$ & $10.98 \pm 0.84$ & - & - & $174.25 \pm 0.27$ & $2.97 \pm 0.68$ & $2.89 \pm 0.58$ & - \\
\hline Fortodi & $10.13 \pm 0.64$ & - & $22.43 \pm 0.21$ & $6.69 \pm 0.47$ & - & $58.57 \pm 0.61$ & - & $21.95 \pm 0.26$ & - \\
\hline Lauren & $9.92 \pm 0.32$ & - & $16.46 \pm 0.25$ & - & $17.67 \pm 0.39$ & - & $2.45 \pm 0.45$ & $3.65 \pm 0.84$ & - \\
\hline Canby & $9.56 \pm 0.35$ & - & $2.27 \pm 0.42$ & - & $91.78 \pm 0.26$ & - & - & - & - \\
\hline Taylor & $8.79 \pm 0.73$ & $1.03 \pm 0.09$ & $3.72 \pm 0.95$ & - & $47.25 \pm 0.87$ & - & - & $11.14 \pm 0.78$ & - \\
\hline Tulameen & $195.51 \pm 0.12$ & $28.09 \pm 0.95$ & $46.48 \pm 0.41$ & - & - & $8.52 \pm 0.93$ & - & $25.06 \pm 0.87$ & - \\
\hline Reveille & $24.24 \pm 0.81$ & $2.42 \pm 0.99$ & $11.84 \pm 0.31$ & - & - & - & - & $12.66 \pm 0.31$ & - \\
\hline Coho & $115.89 \pm 0.71$ & $59.69 \pm 0.89$ & - & - & - & - & - & $14.68 \pm 0.07$ & - \\
\hline Encore & $22.53 \pm 0.85$ & $2.24 \pm 0.99$ & $11.98 \pm 0.30$ & $2.24 \pm 0.59$ & - & - & - & $38.55 \pm 0.75$ & - \\
\hline Herokee & $21.25 \pm 0.12$ & $1.52 \pm 0.34$ & $11.88 \pm 0.70$ & - & - & - & - & $10.89 \pm 0.55$ & - \\
\hline Kitsilano & $113.22 \pm 0.76$ & $9.43 \pm 0.84$ & $27.96 \pm 0.19$ & - & $2.10 \pm 0.09$ & $26.14 \pm 0.39$ & $2.79 \pm 0.84$ & $11.06 \pm 0.38$ & - \\
\hline Chilcotin & $70.25 \pm 0.93$ & $3.67 \pm 0.76$ & $13.98 \pm 0.84$ & - & - & - & - & - & - \\
\hline Titan & $113.61 \pm 0.44$ & $38.26 \pm 0.50$ & $68.79 \pm 0.31$ & - & - & $14.95 \pm 0.63$ & - & $5.43 \pm 0.68$ & - \\
\hline Latham & $23.63 \pm 0.84$ & $3.25 \pm 0.18$ & $13.00 \pm 0.56$ & - & - & $10.24 \pm 0.15$ & - & $7.53 \pm 0.93$ & - \\
\hline Raspberry Nano & $41.28 \pm 0.84$ & $5.12 \pm 0.33$ & $10.04 \pm 0.28$ & - & - & - & - & $4.77 \pm 0.57$ & - \\
\hline Chillieack & - & $29.56 \pm 0.77$ & $54.63 \pm 0.62$ & - & $2.71 \pm 0.54$ & $23.73 \pm 0.88$ & $2.14 \pm 0.38$ & $8.18 \pm 0.35$ & - \\
\hline Triple Crown & - & $5.88 \pm 0.22$ & $30.56 \pm 0.99$ & - & - & $12.33 \pm 0.54$ & - & $7.87 \pm 0.76$ & - \\
\hline Boysenberry & - & - & $20.04 \pm 0.39$ & - & - & - & - & $33.62 \pm 0.86$ & - \\
\hline Shawnee & - & $2.29 \pm 0.79$ & $391.60 \pm 0.48$ & - & $56.01 \pm 0.27$ & - & - & $7.43 \pm 0.43$ & - \\
\hline Honey Queen & $81.50 \pm 0.15$ & $8.83 \pm 0.83$ & $28.34 \pm 0.83$ & - & $33.87 \pm 0.848$ & - & - & $6.57 \pm 0.12$ & - \\
\hline $\begin{array}{l}\text { Full of red } \\
\text { Raspberry }\end{array}$ & $93.39 \pm 0.17$ & $13.45 \pm 0.22$ & $57.85 \pm 0.21$ & - & $313.78 \pm 0.39$ & $6.23 \pm 0.76$ & - & $71.16 \pm 0.61$ & - \\
\hline Autumn Britten & $6.44 \pm 0.67$ & - & $13.45 \pm 0.55$ & $2.33 \pm 0.57$ & $22.44 \pm 0.39$ & - & - & $23.50 \pm 0.19$ & - \\
\hline Autumn Bliss & $47.89 \pm 0.21$ & $4.49 \pm 0.48$ & $10.46 \pm 0.25$ & - & - & $27.60 \pm 0.91$ & $2.25 \pm 0.98$ & $10.97 \pm 0.24$ & - \\
\hline Heritage & $13.76 \pm 0.18$ & - & $18.28 \pm 0.39$ & - & - & - & - & $14.89 \pm 0.59$ & - \\
\hline Killarney & $14.40 \pm 0.24$ & $2.41 \pm 0.86$ & $5.07 \pm 0.74$ & - & - & $16.17 \pm 0.41$ & - & $5.05 \pm 0.64$ & - \\
\hline Kiwigold & $17.46 \pm 0.37$ & $2.15 \pm 0.16$ & $80.68 \pm 0.41$ & - & - & - & - & $5.14 \pm 0.28$ & - \\
\hline Laguo & - & $46.84 \pm 0.14$ & $336.69 \pm 0.83$ & - & - & - & - & $23.74 \pm 0.35$ & - \\
\hline Cangjia & - & $3.49 \pm 0.48$ & - & - & - & - & $5.81 \pm 0.32$ & $6.93 \pm 0.95$ & - \\
\hline Baojia & - & $41.99 \pm 0.78$ & - & - & - & - & - & $8.33 \pm 0.12$ & - \\
\hline Leren & - & $10.49 \pm 0.61$ & - & - & - & - & - & $3.71 \pm 0.98$ & - \\
\hline Nanque & $11.09 \pm 0.52$ & - & $3.18 \pm 0.11$ & $14.65 \pm 0.39$ & - & $2.60 \pm 0.34$ & $3.37 \pm 0.87$ & $6.24 \pm 0.79$ & - \\
\hline Ganchong & $64.17 \pm 0.76$ & $38.58 \pm 0.72$ & $248.13 \pm 0.18$ & - & - & - & - & $10.57 \pm 0.22$ & - \\
\hline Pansheng & $70.63 \pm 0.96$ & $21.54 \pm 0.36$ & $44.30 \pm 0.38$ & - & $2.36 \pm 0.49$ & $7.24 \pm 0.79$ & $2.84 \pm 0.88$ & $21.18 \pm 0.75$ & - \\
\hline Layun & $20.55 \pm 0.92$ & - & $37.69 \pm 0.79$ & $5.71 \pm 0.27$ & - & $11.46 \pm 0.31$ & - & $27.61 \pm 0.78$ & - \\
\hline Huazang & $10.81 \pm 0.14$ & - & $7.19 \pm 0.31$ & - & - & - & - & $11.93 \pm 0.79$ & - \\
\hline
\end{tabular}

${ }^{1}$ Data are expressed as mean value \pm S.D. - signifies not detected. 
Table 5. Total phenolic acid contents in Rubus idaeus L. growing in different regions (mean \pm SD) (mg/100g).

\begin{tabular}{|c|c|c|c|c|c|c|c|c|c|c|c|}
\hline Samples & $\begin{array}{c}\text { Qinghai-Tibetan } \\
\text { Plateau }\end{array}$ & $\begin{array}{l}\text { Northern } \\
\text { Greece [26] }\end{array}$ & Spain [27] & Turkey [24] & $\begin{array}{c}\text { Belgrade } \\
\text { [28] }\end{array}$ & $\begin{array}{c}\text { Norway } \\
\text { [29] }\end{array}$ & $\begin{array}{c}\text { Brazil } \\
{[30]}\end{array}$ & $\begin{array}{c}\text { NewYork } \\
{[31,32]}\end{array}$ & Bursa [33] & $\begin{array}{c}\text { Lithuanian } \\
{[5]}\end{array}$ & $\begin{array}{c}\text { Finland } \\
\text { [34] }\end{array}$ \\
\hline Heritage & $2715.36 \pm 36.77$ & $1905 \pm 58$ & $1232.28 \pm 66.49$ & $3064.64 \pm 51.07$ & - & 297.7 & 446.79 & $512.7 \pm 4.7$ & $1463.7 \pm 22.8$ & - & $317 \pm 5$ \\
\hline Meeker & $5914.37 \pm 73.86$ & $2116 \pm 44$ & - & - & - & - & - & 444 & - & $388.8 \pm 11.3$ & - \\
\hline Autumn Bliss & $1977.74 \pm 21.18$ & $2494 \pm 77$ & $1364.32 \pm 80.14$ & - & $372 \pm 14$ & - & 553.23 & 396 & - & - & - \\
\hline Taylor & $2136.16 \pm 28.12$ & $1891 \pm 76$ & - & - & - & - & - & - & - & - & - \\
\hline Boysenberry & $678.68 \pm 10.03$ & - & - & - & - & - & 319.75 & & - & - & - \\
\hline Kiwigold & $1066.78 \pm 12.18$ & - & - & - & - & - & - & $451.1 \pm 4.5$ & - & - & - \\
\hline AutumnBritten & $896.58 \pm 14.30$ & - & - & - & - & - & - & 367 & - & - & - \\
\hline Boyne & $715.26 \pm 11.16$ & - & - & - & - & - & - & 386 & - & - & - \\
\hline Tulameen & $1489.63 \pm 17.52$ & - & - & - & - & - & - & 386 & - & - & - \\
\hline Coho & $1840.76 \pm 17.30$ & - & - & - & - & - & - & 383 & - & - & - \\
\hline
\end{tabular}




\subsubsection{Scavenging Abilities Against Intracellular Free Radicals}

The toxicities to HepG2 cells of the phenols extracted from five raspberry varieties, including Meeker, Boyne, Tulameen, Laguo, and Baojia, were evaluated at concentrations ranging from 20 to $100 \mu \mathrm{g} / \mathrm{mL}$ in order to confirm the safe doses for cell experiments. As shown in Figure $4 \mathrm{c}$, all five raspberry-extracted phenols presented no significant effects on the survivability of the HepG2 cells at the concentrations tested $(p<0.05)$. The results also indicated that the concentration range could be utilized as safe doses for cell experiments.

As shown in Figure 4d, the scavenging abilities against intracellular ROS of the phenols extracted at concentrations ranging from $20-100 \mu \mathrm{g} / \mathrm{mL}$ from the raspberry varieties Meeker, Boyne, Tulameen, Laguo, and Baojia had dose-response relationships. Baoji-extracted phenols had the highest scavenging ability against ROS, with a ratio of $55.67 \%$, followed by Meeker, Tulameen, and Boyne, in which the ratios were $53.73 \%, 46.83 \%$, and $45.56 \%$, respectively. The scavenging abilities against ROS of phenols from Meeker and Tulameen also showed significant dose-response relationships at low concentrations. However, when the concentration was higher than or equal to $60 \mu \mathrm{g} / \mathrm{mL}$, the extracts displayed no significant increase in ROS scavenging capacity. The phenols extracted from Laguo had relatively weak ROS scavenging ability at concentrations ranging from 20 to $60 \mu \mathrm{g} / \mathrm{mL}$; however, the ROS scavenging ability was enhanced to $24.52 \%$ when the concentration reached $80 \mu \mathrm{g} / \mathrm{mL}$. On the basis of these results, it could be concluded that the antioxidant capacity was highest in the extracted phenols from Baojia, followed by Meeker, Tulameen, Boyne, and Laguo.

\section{Experimental Conditions}

\subsection{Instruments}

High-performance liquid chromatography (HPLC) analysis was performed using an Agilent1260 series HPLC system (Agilent Technologies Co. Ltd., Palo Alto, CA, USA), which was equipped with an online degasser (model G1322B, Agilent Technologies Co. Ltd., Palo Alto, CA, USA), a quaternary pump (model G1311C, Agilent Technologies Co. Ltd., Palo Alto, CA, USA), an autosampler (model G1329B, Agilent Technologies Co. Ltd., Palo Alto, CA, USA), a thermostat column compartment (model G1316B), and an ultraviolet detector (model G4212B, Agilent Technologies Co. Ltd., Palo Alto, CA, USA). The ultrasonic-assisted extraction of raspberry was conducted using an ultrasonic cleaner (KQ-500DE, Kunshan ultrasonic instrument Co., Kunshan, China). Absorbance was detected at $490 \mathrm{~nm}$ using a Multi-Mode Detection Platform (Molecular Devices, San Jose, CA, USA).

\subsection{Materials and Reagents}

Thirty-seven varieties of raspberry were identified by Professor Yourui Suo (Northwest Plateau Institute of Biology, Chinese Academy of Sciences) and were grown in the Qinghai-Tibetan plateau region. These raspberry varieties included 9 local varieties-Laguo, Cangjia, Baojia, Leren, Nanque, Ganchong, Pansheng, Layun, and Huazang - and 28 adventitious varieties-Meeker, Boyne, Tulameen, Fortodi, Lauren, Canby, Taylor, Tulameen, Reveille, Coho, Encore, Herokee, Kitsilano, Chilcotin, Titan, Latham, Raspberry Nano, Chillieack, Triple Crown, Boysenberry, Shawnee, Honey Queen, Full of Red Raspberry, Autumn Britten, Autumn Bliss, Heritage, Killarney, and Kiwigold.

Nine phenol standards, including gallic acid, catechin, chlorogenic acid, vanillic acid, syringic acid, cumaric acid, ferulic acid, rosemary acid, and quercetin, were of chromatographic grade and purchased from the Sigma Reagent Co. (St. Louis, MO, USA). Analytical graded chloroform, petroleum ether, and ethanol were obtained from the Shanghai Chemical Reagent Co. (Shanghai, China). Ultra-pure water was supplied by Watsons (Guangzhou, China). All other reagents used were of analytical grade unless otherwise stated. 


\subsection{Preparation of Standard Solutions}

Stock solutions were first separately prepared in $90 \%$ acetonitrile. The stock solutions were then used to prepare the mixed standards (concentration of $1 \times 10^{-3} \mathrm{~mol} / \mathrm{L}$ ) containing the nine phenols by diluting the corresponding stock solution with acetonitrile. Other diluted mixed standards were prepared by diluting the corresponding stock solutions with acetonitrile. All solutions were stored in a refrigerator $\left(4^{\circ} \mathrm{C}\right)$ until further use.

\subsection{Sample Preparation}

Preparation of analytical samples: Raspberry samples were dried in an electrical furnace at 60 ${ }^{\circ} \mathrm{C}$ until their weights were constant. The dried samples were then milled and kept at $4{ }^{\circ} \mathrm{C}$ until subsequent use. In the extraction of phenols, each sample was weighed to $50 \mathrm{mg}$ in a brown ampere bottle and then dissolved with $2.0 \mathrm{~mL}$ of $65 \%$ ethanol. The sample was then ultra-sonicated at $50{ }^{\circ} \mathrm{C}$ for $50 \mathrm{~min}$ and centrifuged at $4000 \mathrm{rpm}$ for $10 \mathrm{~min}$. The supernatant was collected and filtered through a $0.22-\mu \mathrm{m}$ nylon filter and then stored in a refrigerator $\left(4^{\circ} \mathrm{C}\right)$ until further analysis.

Preparation of antioxidant samples: In the extraction of phenols, each sample was weighed to 50 $\mathrm{g}$ and dissolved in $2000 \mathrm{~mL}$ of $65 \%$ ethanol. Volumes of the samples were first minimized to $100 \mathrm{~mL}$ in a vacuum at $40{ }^{\circ} \mathrm{C}$. The samples were then loaded into a XAD-7 chromatographic column $(4.0 \mathrm{~cm} \times$ $60 \mathrm{~cm}$, Yuwang Company, Shandong, China) and underwent adsorption for $1 \mathrm{~h}$. The column was then eluted with acidified 1\% ethanol (diluted in deionized water) at a flow rate of $2 \mathrm{~mL} / \mathrm{min}$ to remove unbound and/or loosely bound non-phenol substances. The phenols were finally eluted using acidified absolute ethanol. The eluent was further concentrated in a vacuum at $40^{\circ} \mathrm{C}$, followed by freeze-drying to obtain phenol powders. A Sephadex LH20 glucan gel chromatographic column $(1.8 \mathrm{~cm} \times 100 \mathrm{~cm}$, Yuwang Company, Shandong, China) was first equilibrated with phosphate-buffered saline (PBS) at $\mathrm{pH}$ 7.0. The extracted phenols weighed to $50 \mathrm{mg}$ were eluted using PBS to remove phenols. The eluent was concentrated in a vacuum and freeze-dried to obtain the final extracted phenol samples. The samples were stored in the dark at $20^{\circ} \mathrm{C}$.

\subsection{Experimental Design and Data Analysis}

A three-variable and three-level Box-Behnken design (BBD) was applied to optimize the extraction process. Combined with the response surface methodology (RSM), BBD has the advantages of being efficient and simple, which can further provide interaction effects in the response values [35,36]. An adventitious variety, Meeker, was chosen to be a representative raspberry in the optimization of phenol extraction. The input variables and their values chosen in the optimization process were: $\mathrm{X} 1$, volume of extraction reagent (values $=1,1.5$, and $2 \mathrm{~mL}$ ); $\mathrm{X} 2$, extraction time (values $=40,50$, and $60 \mathrm{~min}$ ); and $\mathrm{X} 3$, extraction temperature (values $=35,45$, and $55^{\circ} \mathrm{C}$ ). The dependent variable $(\mathrm{Y})$ was the peak area. The experimental designs for the extraction process are shown in Table 1 . The experimental data were analyzed using Design Expert software (Version 7.1.6, Stat-Ease Inc., Minneapolis, MN, USA).

\subsection{Biochemical Assays}

Antioxidant activities of five widely grown raspberry varieties, including Meeker, Boyne, Tulameen, Laguo, and Baojia, were investigated.

\subsection{1. $\mathrm{DPPH}^{-}$and $\mathrm{ABTS}^{-}$Free Radical Scavenging Activity Assays}

$\mathrm{DPPH}^{-}$free radical scavenging activity $[37,38]$ : DPPH solution was prepared in absolute ethanol at a concentration of $0.1 \mathrm{mmol} / \mathrm{L}$ and stored in the dark. A vitamin C (Vc) solution of $0.5 \mathrm{mg} / \mathrm{mL}$ was used as the reference. The freeze-dried raspberry phenols were diluted to various concentrations. Three types of equal-volume mixture solutions $(2 \mathrm{~mL}$ each) were then prepared and measured for their absorbances to obtain parameters for the calculation of $\mathrm{DPPH}^{-}$free radical scavenging activity: (1) $\mathrm{A}_{\text {sample }}{ }^{1}$ is the absorbance of samples and the DPPH solution mixture, which was prepared by first 
mixing the two components and then letting it stand in the dark for 30 min prior to measurement; (2) $\mathrm{A}_{\text {control }}{ }^{1}$ is the absorbance of the DPPH solution and solvent (i.e., distilled water or the corresponding buffer solutions) mixture; and (3) $\mathrm{A}_{\text {blank }}{ }^{1}$ is the absorbance of the testing sample and absolute ethanol mixture. The $\mathrm{DPPH}^{-}$free radical scavenging activity was expressed as the scavenging ratio percentage, calculated using the following equation:

$$
\text { Scavenging ratio of DPPH }(\%)=\left[1-\left(\mathrm{A}_{\text {sample }}{ }^{1}-\mathrm{A}_{\text {blank }}{ }^{1}\right) \div \mathrm{A}_{\text {control }}{ }^{1}\right] \times 100
$$

ABTS $^{-}$free radical scavenging activity: Previous literature was taken as a reference [39], and absorbance values were measured on a spectrophotometer at $734 \mathrm{~nm}$. First, the mother solution for the ABTS assay was prepared and stored in the dark for 12-16 h. Prior to use, the mother solution was diluted to appropriate concentrations using PBS and measured for the absorbance, which was deducted by the absorbance of the corresponding PBS blank control to obtain $\mathrm{A}_{734}=0.7( \pm 0.02)$. To construct a standard curve, $10 \mathrm{mmol} / \mathrm{L}$ Trolox standard solution (Sigma Reagent Co., St. Louis, MO, USA) was first diluted to various concentrations. The standard curve was then plotted according to the scavenging ratio to ABTS [40]. The antioxidant ability with Trolox equivalency was calculated using the following equation:

$$
\text { ABTS scavenging ratio }(\%)=\left[1-\left(\mathrm{A}_{\text {sample }}{ }^{2}-\mathrm{A}_{\text {blank }^{2}}{ }^{2}\right) \div \mathrm{A}_{\text {control }}{ }^{2}\right] \times 100 \%
$$

where $\mathrm{A}_{\text {sample }}{ }^{2}$ is the absorbance of the testing sample, $\mathrm{A}_{\text {blank }}{ }^{2}$ is the sample background absorbance, and $\mathrm{A}_{\text {control }}{ }^{2}$ is the absorbance when the sample is not present (i.e., buffer alone).

\subsubsection{Assays of the Intracellular Activities of Phenols}

Cell preparation: HepG2 cells were cultured in Dulbecco's modified eagle medium (DMEM) containing $10 \%$ fetal calf serum. Cell passages were conducted when the cell density achieved $80-90 \%$, and stable and well-grown cells were used for further experiments. Cells at log-phase were seeded in a 96-well plate for subsequent experiments.

Cell toxicity assay: cellular toxicological evaluation was carried out using an MTT (3-(4,5-dimethylthiazol-2-yl)-2,5-diphenyltetrazolium bromide) assay. Cells were first seeded in 96-well plates at a cell density of $8 \times 10^{4}$ cells $/ \mathrm{mL}$ and cultured at $37^{\circ} \mathrm{C}$ for $24 \mathrm{~h}$. After that, the culture medium was replaced with the incomplete culture medium supplemented with various concentrations of phenols, and it was further cultured at the same temperature for $24 \mathrm{~h}$. Thereafter, the fluid was removed, and $200 \mu \mathrm{L}$ of incomplete culture medium containing MTT solution was added to obtain a final concentration of $0.5 \mathrm{mg} / \mathrm{mL}$, which continued to incubate at $37^{\circ} \mathrm{C}$. After $4 \mathrm{~h}$ of incubation, the fluid was removed, and $150 \mu \mathrm{L}$ of dimethyl sulfoxide (DMSO) was added. The plate was placed on a shaker running at low speed for 5 min to allow for mixing of the cells and DMSO. Finally, a Multi-Mode Detection Platform was employed, and the absorbance at $570 \mathrm{~nm}$ was measured.

Intracellular ROS detection: HepG2 Cells were seeded in 96-well plates at a cell density of $8 \times 10^{4}$ cells/mL $(200 \mu \mathrm{L} /$ well $)$ and incubated under $5 \% \mathrm{CO}_{2}$ at $37^{\circ} \mathrm{C}$ for $24 \mathrm{~h}$. After $24 \mathrm{~h}$, the medium was carefully removed, and the cells were then incubated in DMEM medium, without serum, supplemented with phenol samples under $5 \% \mathrm{CO}_{2}$ at $37^{\circ} \mathrm{C}$ for $24 \mathrm{~h}$. This was followed by the addition of $200 \mu \mathrm{L}$ of HBSS (Hank's buffered salt solution) containing $25 \mu \mathrm{mol} / \mathrm{L}$ of $2^{\prime}-7^{\prime}$ - dichlorodihydrofluorescein diacetate (DCFH-DA) and was further incubated for $1 \mathrm{~h}$ in the same conditions. After that, the fluid was removed, and the cells were washed three times with HBSS solution. The cells were then treated with $100 \mu \mathrm{L}$ of $0.6 \mathrm{~mol} / \mathrm{L} \mathrm{AAPH} \mathrm{(2,2'-azobis(2-amidinopropane)} \mathrm{dihydrochloride)} \mathrm{and} \mathrm{incubated} \mathrm{for}$ $30 \mathrm{~min}$ in the $\mathrm{CO}_{2}$ incubator in the same conditions. The Multi-Mode Detection Platform was finally employed, and fluorescence intensities were measured at the excitation and emission wavelengths of 485 and $530 \mathrm{~nm}$, respectively. 


\section{Conclusions}

In this work, an efficient method was developed for the rapid extraction and separation of nine phenols, including gallic acid, catechin, chlorogenic acid, vanillic acid, syringic acid, cumaric acid, ferulic acid, rosemary acid, and quercetin, from 37 different varieties of raspberry and for antioxidative activities research. The analysis of phenol contents from various raspberry varieties indicated that the exotic varieties Baojia, Meeker, Tulameen, and Boyne had significantly higher phenol contents than local varieties, such as Laguo. In turn, these varieties possessed higher antioxidant activities, as demonstrated in the results from scavenging activities against DPPH and ABTS free radicals and from intracellular ROS experiments. This is the first report on the quantitative analyses of 9 phenolic compounds and their antioxidant activities from 37 varieties of raspberry grown in the Qinghai-Tibetan Plateau region. On this basis, this research provides a theoretical framework for the various choices of raspberry suitable for product development in the Qinghai-Tibetan Plateau region.

Author Contributions: Y.W., J.L., and W.Z. conceived and designed the experiments. Y.W. and J.L. performed the research with the help of G.L., S.Z., Y.Z., and J.X. Y.W. and J.L. analyzed the data and wrote the manuscript. W.Z. critically revised the draft and edited the English. All authors discussed the results and revised the manuscript.

Funding: This work was supported by the Project of Qinghai Science \& Technology Department (2019-ZJ-965Q), the Project of Qinghai Science \& Technology Department (2019-NK-106), and The Open Project of State Key Laboratory of Plateau Ecology and Agriculture, Qinghai University (2018-ZZ-06).

Conflicts of Interest: The authors declare that there are no conflict of interest.

\section{References}

1. Mullen, W.; Stewart, A.J.; Lean, M.E.; Gardner, P.; Duthie, G.G.; Crozier, A. Effect of freezing and storage on the phenolics, ellagitannins, flavonoids, and antioxidant capacity of red raspberries. J. Agric. Food Chem. 2002, 50, 5197-5201. [CrossRef] [PubMed]

2. Mullen, W.; McGinn, J.; Lean, M.E.; MacLean, M.R.; Gardner, P.; Duthie, G.G.; Yokota, T.; Crozier, A. Ellagitannins, flavonoids, and other phenolics in red raspberries and their contribution to antioxidant capacity and vasorelaxation properties. J. Agric. Food Chem. 2002, 50, 5191-5196. [CrossRef] [PubMed]

3. González-Barrio, R.; Edwards, C.A.; Crozier, A. Colonic catabolism of ellagitannins, ellagic acid and raspberry anthocyanins: In vivo and in vitro studies. Drug Metab. Dispos. 2011, 39, 1680-1688. [CrossRef] [PubMed]

4. Verbeyst, L.; Van Crombruggen, K.; Van der Plancken, I.; Hendrickx, M.; Van Loey, A. Anthocyanin degradation kinetics during thermal and high pressure treatments of raspberries. J. Food Eng. 2011, 105, 513-521. [CrossRef]

5. Bobinaitè, R.; Viškelis, P.; Venskutonis, P.R. Variation of total phenolics, anthocyanins, ellagic acid and radical scavenging capacity in various raspberry (Rubus spp.) cultivars. Food Chem. 2012, 132, 1495-1501. [CrossRef] [PubMed]

6. Lee, J.; Dossett, M.; Finn, C.E. Anthocyanin fingerprinting of true bokbunja (Rubus coreanus Miq.) fruit. J. Funct. Foods 2013, 5, 1985-1990. [CrossRef]

7. Alves, G.H.; Ferreira, C.D.; Vivian, P.G.; Monks, J.L.F.; Elias, M.C.; Vanier, N.L.; de Oliveira, M. The revisited levels of free and bound phenolics in rice: Effects of the extraction procedure. Food Chem. 2016, 208, 116-123. [CrossRef]

8. Andreasen, M.F.; Kroon, P.A.; Williamson, G.; Garcia-Conesa, M.-T. Esterase activity able to hydrolyze dietary antioxidant hydroxycinnamates is distributed along the intestine of mammals. J. Agric. Food Chem. 2001, 49, 5679-5684. [CrossRef]

9. Yu, L.; Haley, S.; Perret, J.; Harris, M.; Wilson, J.; Qian, M. Free radical scavenging properties of wheat extracts. J. Agric. Food Chem. 2002, 50, 1619-1624. [CrossRef]

10. Yu, L.; Perret, J.; Harris, M.; Wilson, J.; Haley, S. Antioxidant properties of bran extracts from "Akron" wheat grown at different locations. J. Agric. Food Chem. 2003, 51, 1566-1570. [CrossRef]

11. Vu, K.D.; Carlettini, H.; Bouvet, J.; Côté, J.; Doyon, G.; Sylvain, J.-F.; Lacroix, M. Effect of different cranberry extracts and juices during cranberry juice processing on the antiproliferative activity against two colon cancer cell lines. Food Chem. 2012, 132, 959-967. [CrossRef] 
12. Vattem, D.A.; Jang, H.D.; Levin, R.; Shetty, K. Synergism of cranberry phenolics with ellagic acid and rosmarinic acid for antimutagenic and DNA protection functions. J. Food Biochem. 2006, 30, 98-116. [CrossRef]

13. Caillet, S.; Côté, J.; Sylvain, J.-F.; Lacroix, M. Antimicrobial effects of fractions from cranberry products on the growth of seven pathogenic bacteria. Food Control. 2012, 23, 419-428. [CrossRef]

14. Caillet, S.; Côté, J.; Doyon, G.; Sylvain, J.-F.; Lacroix, M. Antioxidant and antiradical properties of cranberry juice and extracts. Food Res. Int. 2011, 44, 1408-1413. [CrossRef]

15. Shekarchi, M.; Hajimehdipoor, H.; Saeidnia, S.; Gohari, A.R.; Hamedani, M.P. Comparative study of rosmarinic acid content in some plants of Labiatae family. Pharmacogn. Mag. 2012, 8, 37. [PubMed]

16. Hajazimi, E.; Landberg, R.; Zamaratskaia, G. Simultaneous determination of flavonols and phenolic acids by HPLC-CoulArray in berries common in the Nordic diet. LWT-Food Sci. Technol. 2016, 74, 128-134. [CrossRef]

17. Kalia, K.; Sharma, K.; Singh, H.P.; Singh, B. Effects of extraction methods on phenolic contents and antioxidant activity in aerial parts of Potentilla atrosanguinea Lodd. and quantification of its phenolic constituents by RP-HPLC. J. Agric. Food Chem. 2008, 56, 10129-10134. [CrossRef]

18. Oniszczuk, A.; Olech, M. Optimization of ultrasound-assisted extraction and LC-ESI-MS/MS analysis of phenolic acids from Brassica oleracea L. var. sabellica. Ind. Crop. Prod. 2016, 83, 359-363. [CrossRef]

19. Hsu, B.Y.; Lin, S.W.; Inbaraj, B.S.; Chen, B.H. Simultaneous determination of phenolic acids and flavonoids in Chenopodium formosanum Koidz.(djulis) by HPLC-DAD-ESI-MS/MS. J. Pharmaceut. Biomed. 2017, 132, 109-116. [CrossRef]

20. Lee, J.; Chan, B.L.S.; Mitchell, A.E. Identification/quantification of free and bound phenolic acids in peel and pulp of apples (Malus domestica) using high resolution mass spectrometry (HRMS). Food Chem. 2017, 215, 301-310. [CrossRef]

21. Dias, F.S.; David, J.M.; David, J.P. Determination of phenolic acids and quercetin in Brazilian red wines from Vale do São Francisco region using liquidliquid ultrasound-assisted extraction and HPLC-DAD-MS. J. Brazil Chem. Soc. 2016, 26, 1055-1059.

22. Fontana, A.R.; Antoniolli, A.; Bottini, R. Development of a high performance liquid chromatography method based on a core-shell column approach for the rapid determination of multiclass polyphenols in grape pomaces. Food Chem. 2016, 192, 1-8. [CrossRef] [PubMed]

23. Manns, D.C.; Mansfield, A.K. A core-shell column approach to a comprehensive high-performance liquid chromatography phenolic analysis of Vitis vinifera L. and interspecific hybrid grape juices, wines, and other matrices following either solid phase extraction or direct injection. J. Chromatogr. A 2012, 1251, 111-121. [CrossRef] [PubMed]

24. Türkben, C.; Sarıburun, E.; Demir, C.; Uylaşer, V. Effect of Freezing and Frozen Storage on Phenolic Compounds of Raspberry and Blackberry Cultivars. Food Anal. Methods. 2010, 3, 144-153. [CrossRef]

25. Kula, M.; Majdan, M.; Głód, D.; Krauze-Baranowska, M. Phenolic composition of fruits from different cultivars of red and black raspberries grown in Poland. J. Food Compos. Anal. 2016, 52, 74-82. [CrossRef]

26. Pantelidis, G.E.; Vasilakakis, M.; Manganaris, G.A.; Diamantidis, G.R. Antioxidant capacity, phenol, anthocyanin and ascorbic acid contents in raspberries, blackberries, red currants, gooseberries and Cornelian cherries. Food Chem. 2007, 102, 777-783. [CrossRef]

27. de Ancos, B.; González, E.M.; Cano, M.P. Ellagic Acid, Vitamin C, and Total Phenolic Contents and Radical Scavenging Capacity Affected by Freezing and Frozen Storage in Raspberry Fruit. J. Agric. Food Chem. 2008, 56, 10129-10134. [CrossRef]

28. Maksimović, J.J.D.; Milivojević, J.M.; Poledica, M.M.; Nikolić, M.D.; Maksimović, V.M. Poledica b.Profiling antioxidant activity of two primocane fruiting red raspberry cultivars (Autumn bliss and Polka). J. Food Compos. Anal. 2013, 31, 173-179. [CrossRef]

29. Mazur, S.P.; Nes, A.; Wold, A.B.; Remberg, S.F.; Aaby, K. Quality and chemical composition of ten red raspberry (Rubus idaeus L.) genotypes during three harvest seasons. Food Chem. 2014, 160, 233-240. [CrossRef]

30. Maro, L.A.C.; Pio, R.; Guedes, M.N.S.; de Abreu, C.M.P.; Curi, P.N. Bioactive compounds, antioxidant activity and mineral composition of fruits of raspberry cultivars grown in subtropical areas in Brazil. Fruits 2013, 68, 209-217. [CrossRef]

31. Liu, M.; Li, X.Q.; Weber, C.; Lee, C.Y.; Brown, J.; Liu, R.H. Antioxidant and Antiproliferative Activities of Raspberries. J. Agric. Food Chem. 2002, 50, 2926-2930. [CrossRef] [PubMed] 
32. Weber, C.A.; Perkins-Veazie, P.; Moore, P.P. Variability of antioxidant content in raspberry germplasm. In IX International Rubus and Ribes Symposium; Banados P.: Pucón, Chile, 2005; Volume 777, pp. 493-498.

33. Sariburun, E.; Şahin, S.; Demir, C.; Türkben, C.; Uylaşer, V. Phenolic content and antioxidant activity of raspberry and blackberry cultivars. J. Food Sci. 2010, 75, 328-335. [CrossRef] [PubMed]

34. Anttonen, M.J.; Karjalainen, R.O. Environmental and genetic variation of phenolic compounds in red raspberry. J. Food Compos. Anal. 2005, 18, 759-769. [CrossRef]

35. Yeh, W.-C. A MCS-RSM approach for network reliability to minimise the total cost. Int. J. Adv. Manuf. Tech. 2003, 22, 681-688. [CrossRef]

36. Ebrahimi-Najafabadi, H.; Leardi, R.; Jalali-Heravi, M. Experimental design in analytical chemistry-Part II: Applications. J. AOAC Int. 2014, 97, 12-18. [CrossRef]

37. Li, C.; Du, H.; Wang, L.; Shu, Q.; Zheng, Y.; Xu, Y.; Zhang, J.; Zhang, J.; Yang, R.; Ge, Y. Flavonoid composition and antioxidant activity of tree peony (Paeonia section Moutan) yellow flowers. J. Agric. Food Chem. 2009, 57, 8496-8503. [CrossRef]

38. López-Sebastián, S.; Ramos, E.; Ibánez, E.; Bueno, J.M.; Ballester, L.; Tabera, J.; Reglero, G. Dearomatization of antioxidant rosemary extracts by treatment with supercritical carbon dioxide. J. Agric. Food Chem. 1998, 46, 13-19. [CrossRef]

39. Leite, A.V.; Malta, L.G.; Riccio, M.F.; Eberlin, M.N.; Pastore, G.M.; Marostica Junior, M.R. Antioxidant potential of rat plasma by administration of freeze-dried jaboticaba peel (Myrciaria jaboticaba Vell Berg). J. Agric. Food Chem. 2011, 59, 2277-2283. [CrossRef]

40. Kang, W.; Wang, J. In vitro antioxidant properties and in vivo lowering blood lipid of Forsythiasuspense leaves. Med. Chem. Res. 2010, 19, 617-628. [CrossRef]

Sample Availability: Samples of the Raspberry are available from the authors.

(C) 2019 by the authors. Licensee MDPI, Basel, Switzerland. This article is an open access article distributed under the terms and conditions of the Creative Commons Attribution (CC BY) license (http://creativecommons.org/licenses/by/4.0/). 